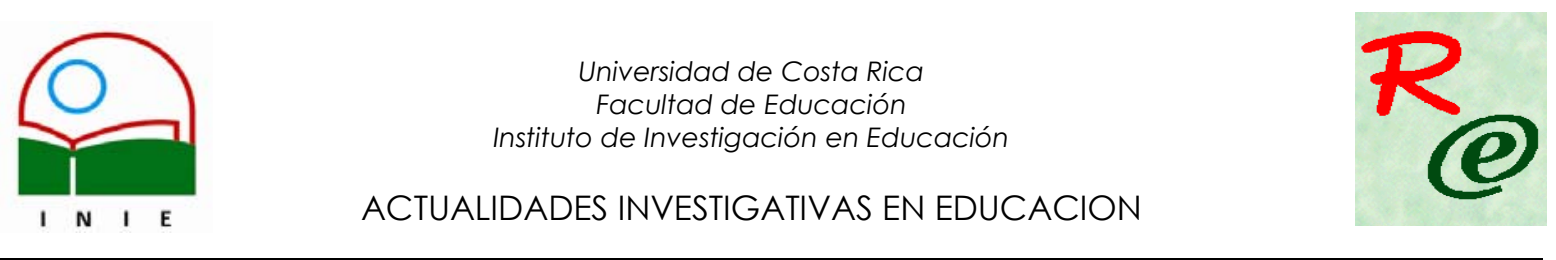

\title{
ENSEÑANZA CÍVICA EN EL PERÍODO OLIGÁRQUICO LIBERAL EN COSTA RICA, 1886-1920: UN ACERCAMIENTO DESDE LAS PERSPECTIVAS TEÓRICAS DEL GÉNERO Y DE LA EDUCACIÓN CÍVICA
}

\author{
CIVIC TEACHING IN THE LIBERAL OLIGARCHIC PERIOD IN COSTA RICA, 1886-1920: \\ AN APPROACH FROM THE THEORETIC PERSPECTIVES OF THE GENDER \\ AND THE CIVIC EDUCATION
}

\begin{abstract}
María de los Ángeles Palacios Robles ${ }^{1}$
Resumen: La Educación Cívica es una materia que se introdujo en el plan de estudio de las escuelas y colegios de Costa Rica, a partir de la Reforma Educativa que plantea Mauro Fernández en 1886. El contexto histórico en que se produce es de neto predominio oligárquico-liberal-masculino. En correspondencia con este sistema, la educación y, muy particularmente la educación cívica, se constituye en un medio de socialización e ideologización, en torno a los férreos valores e intereses patriarcales que dominan a la sociedad costarricense en este período.

¿De qué manera se instaura el sistema patriarcal en nuestra cultura? ¿Cómo y por qué la Educación Cívica es un transmisor y reproductor de ese sistema en el período oligárquico liberal en Costa Rica? Estas interrogantes surgen a partir de esas afirmaciones $y$, es por ello, que las reflexiones que se presentan en este artículo, pretenden analizar la Educación Cívica desde las perspectivas teóricas de género y de la educación cívica, como fenómeno educativo multidimensional para tratar de captar su funcionamiento en el marco del período oligárquico-liberal en Costa Rica durante los años de 1886 a 1920 en que se instaura para el país, otro conjunto de planes y programas educativos.
\end{abstract}

Palabras claves: EDUCACIÓN CÍVICA/ SISTEMA PATRIARCAL/ OLIGÁRQUICO-LIBERAL/

\begin{abstract}
Civic Education is a subject that was introduced in the scholastics plan of Costa Rican elementary and high schools beginning with the Educational Reform that was proposed by Mauro Fernández in 1886. The historical context that it took place in was predominantly oligarchic-liberal-male; in keeping with this system, education and, very particularly, civic education, became a means for socialization, surrounding the firm and uncompromising values and patriarchal interests that dominated Costa Rican society of the time.

¿Haw was the patriarchal system established in our cultural? ¿How and why is Civic Education a transmitter and reproducer of that system in the liberal oligarchic period of Costa Rica? These are questions that arise as a result of those assertions and that is why the reflections offered in this article mean to analyze Civic Education from the common theoretical standpoint and Civic Education as a multidimensional educational phenomenon to attempt to pinpoint its functionality within the period comprised by the years from 1886 to 1920, in which another set educational plans and programs was established in the country.
\end{abstract}

Key words: CIVIC EDUCATION/ PATRIARCHAL SYSTEM/ LIBERAL-OLIGARCHIC/

\footnotetext{
1 Licenciada en Historia, Bachiller en la Enseñanza de los Estudios Sociales, ambos títulos de la Universidad de Costa Rica. Estudiante del sistema de postgrado para obtener la Maestría Académica en Literatura Latinoamericana. Ha laborado en la Universidad Estatal a Distancia (UNED), donde ofreció diversos cursos en el área de investigación para la Licenciatura en Educación Cívica. Actualmente es profesora en la Universidad de Costa Rica donde imparte Historia de la Cultura para los cursos integrados de Humanidades en la Escuela de Estudios Generales.
}

Correo electrónico: marypalacios2003@costarricense.cr

Artículo recibido: 18 de enero, 2005

Aprobado: 24 de abril, 2006 


\section{Introducción}

En el año de 1886, se llevan a cabo una serie de medidas educativas que en su conjunto reciben el nombre de La Reforma. Con ella se establece La Instrucción Moral y Cívica, como materia obligatoria en los planes y programas educativos del país. Se instaura dentro de un modelo, inspirado en el pensamiento liberal y en correspondencia con las necesidades del régimen político y económico. Al mismo tiempo, se anuncian los objetivos primordiales que orientan la educación y que perfilan el papel ideologizante que ésta va a tomar. La Ley Fundamental de Educación Pública señala que dentro de los fines, metas u objetivos de la educación costarricense, se encuentran:

Art.2. a. La formación de ciudadanos amantes de la Patria, conscientes de sus deberes, de sus derechos y de sus libertades fundamentales, con profundo sentido de responsabilidad y de respeto a la dignidad humana.

b. Contribuir al desenvolvimiento pleno de la personalidad humana.

c. Formar ciudadanos para una democracia en que se concilien los intereses del individuo con los de la humanidad (Alfaro, 1984, p. 35).

Por su parte, Don Mauro Fernández, gestor de La Reforma Educativa proclama:

Pensad que es en la escuela, el lugar donde debe formarse el ciudadano, que allí es donde aprende a amar la patria y sus instituciones... y allí es donde se le enseña a pensar a raciocinar, para no ser más tarde instrumento de pasiones e intereses ajenos, sino el guardián de sus propios derechos (Memorias, 1885, p. 8).

El capítulo I, artículo 7 de la Ley General de Educación Común establece que:

El mínimum de instrucción obligatoria comprende las siguientes materias: lectura, escritura, aritmética (las cuatro reglas y el sistema métrico decimal), geometría objetiva, nociones de geografía universal y particular de Costa Rica, Historia de Costa Rica, ejercicios prácticos de lenguaje, gimnástica, MORAL E INSTRUCCIÓN CÍVICA. PARA LAS NIÑAS SERÁ OBLIGATORIO ADEMÁS EL CONOCIMIENTO DE LABORES DE MANO Y NOCIONES DE ECONOMÍA DOMÉSTICA Y PARA LOS VARONES EL CONOCIMIENTO DE LOS EJERCICIOS MILITARES MÁS SENCILLOS y en las campiñas, nociones de agricultura (ANCR. Folio 2).

A los maestros, encargados de la enseñanza en las escuelas públicas, se les asigna especialmente las siguientes obligaciones: 
Art.48. 1. A dar cumplimiento a la presente ley y a los programas y reglamentos que se dictaren para las escuelas. 2. A dirigir personalmente la educación e instrucción de los niños que estén a su cargo, preocupándose con igual solicitud de todos, sin perder ocasión de inculcarles los preceptos de la moral e inspirarles el sentimiento del deber, el amor a la patria, el respeto de las instituciones nacionales y el apego a las libertades constitucionales (ANCR. Folio 26).

De esta manera, se instaura formalmente la Instrucción Cívica, bajo un modelo educativo que separa los contenidos que se les debe enseñar a ambos sexos. Afirma para las niñas un aprendizaje en torno a los trabajos domésticos, como ámbito de acción por excelencia y, para los niños, el ejercicio de las labores militares. Una vez institucionalizado este discurso, se le encarga al maestro, a dar cumplimiento e inculcar estos preceptos, sin perder ocasión.

A partir de este cuadro general, los programas y textos de Educación Cívica y Moral que se emiten para los años de 1886 a 1920 se encargan también de reproducir en el seno de la sociedad costarricense, unos contenidos que sustentan la desigualdad entre lo masculino y lo femenino. El hombre encuentra justificación para ejercer el poder y el dominio en lo político, económico, social, cultural e ideológico. Mientras que la mujer es relegada al ámbito doméstico como ama de casa pero, no ciudadana. Considerada como un cero; va a sufrir exclusión y nulidad.

Los programas de Moral y de Instrucción Cívica que se emiten para la enseñanza primaria y secundaria en este período, son recurrentes en los siguientes contenidos: Formas de gobierno, poderes de la República, derechos y deberes de los ciudadanos, el sufragio, cargos públicos, autoridades y legislación entre otros. Igualmente, el texto que de forma oficial se utiliza para la enseñanza de estos contenidos, Instrucción Cívica, de Ricardo Jiménez Oreamuno, desarrolla estos temas.

Este texto asume, por ejemplo, al gobierno republicano, como el paradigma ideológico que se adjudican las clases dominantes criollas después de la independencia, el cual sustenta el proyecto político de la sociedad del sector liberal de la oligarquía durante el siglo XIX. Este tipo de gobierno presenta características, como las que se señalan a continuación:

1. Propio, es decir que ninguna nación extraña dirige su política.

2. Todos los ciudadanos tienen la facultad de intervenir en el manejo de la cosa pública. 
3. Representativo, pues los funcionarios, cualquiera que sea su categoría, no son dueños, sino depositarios de la autoridad que ejercen y responsables ante la nación, a quien representan, de todos sus actos; ninguna persona puede conservar perpetuamente un destino o cargo público (Jiménez, 1898, p. 16).

Mediante estos elementos discursivos se presenta, al gobierno republicano como efectivamente propio, representativo, en el cual todos los ciudadanos participan de la cosa pública. Sin embargo, aunque el pueblo es llamado a ejercer el poder, en la práctica está excluido de tal conducción. Una pequeña élite de ciudadanos económica y socialmente relevantes es la que ejerce el control. Veamos por qué.

Si bien la Constitución reconoce a los individuos derechos inviolables, estos se encuentran altamente condicionados. Ejemplo de ello lo constituye el derecho de igualdad. En ese período, la igualdad que se proclama, es ante la ley y en dos sentidos, económico y político. El económico trata de cómo "todos tenemos la misma libertad de trabajo, la misma libertad para adquirir bienes y disponer de ellos para contratar" (Jiménez, 1898, p. 18). En lo político la igualdad ante la ley consiste en "ser común a todos los individuos la libertad de palabra, de reunión, de conciencia, de ir y venir..., y en gozar todos los ciudadanos el derecho de elección y de elegibilidad" (Jiménez, 1898, p. 19). Sin embargo, niegan el derecho a votar y a ser elegidas a las personas que presenten las siguientes objeciones:

1. Quien ni siquiera soporta sus propios gastos de vida.

2. Quien no sabe leer ni escribir porque, "sería conceder a la pereza y a la total ignorancia un poder, que ningún derecho tienen de ejercer un poder peligrosísimo para quienes no sufren sus consecuencias".

¿Quiénes son entonces, los que tienen acceso a la ciudadanía y participan en el sufragio?

\section{La gran masa no, porque}

las grandes multitudes son muy propias para encenderse en iras, generosas o brutales $y$, desde que la pasión adquiere la preponderancia en un cuerpo deliberativo, las injusticias y el desacierto son los resultados inevitables. Además, entre las funciones que deben desempeñar los poderes públicos, hay muchas cuyo descargo exige aptitudes y conocimientos especiales que solo reúne, relativamente, un limitado número de personas. (Jiménez, 1898, p. 20)

Tampoco pueden participar "Ios insanos de espíritu ni las mujeres". Estas no gozan de la ciudadanía y las razones "de peso" que se dan son que 
La mujer por su organización cerebral es un ser esencialmente sensible, apasionado y por lo mismo incapaz de guiarse por la idea de justicia, que es la base del buen gobierno de los pueblos; que el hogar doméstico y no la plaza pública es el lugar propio para el ejercicio de las actividades femeninas: y que no siendo la mujer apta para el servicio militar no debe compartir con los hombres el poder político (Jiménez, 1898, p.34).

Estas afirmaciones son altamente reveladores porque constatan al menos tres elementos:

1. La exclusión y el estado de nulidad que someten a la participación femenina en los procesos políticos.

2. Los juicios de valor que sustentan tal exclusión se fundamentan en:

a. La organización cerebral, lo cual implica una descalificación por orden "natural".

b. Se apareja con los insanos de espíritu, los locos, los poseídos por el mal.

c. La forma en que la sensibilidad y la pasión se consideran atributos femeninos que confirman estereotipos, mediante los cuales justifican esta exclusión.

d. Asimismo, se le considera incapaz de ejercer la justicia, debido a que se rige por estos estereotipos.

e. La mujer queda confinada al ámbito doméstico- privado.

f. Le quitan la capacidad de ser heroína al no ejercer el servicio militar.

g. Por tanto, no debe compartir con los hombres el poder político.

3. El modelo oligárquico de acceso al poder excluye también al pueblo- nación de la vida político-electoral.

En esa medida, el poder y la autoridad son ejercidos por un personal reducido, selecto y de apabullante dominio masculino.

Una Instrucción Cívica que se enseña bajo estos contenidos, es un mecanismo más del sistema patriarcal para asegurar y perpetuar su poderío. La educación se constituye en un medio de socialización e ideologización, en torno a los férreos valores e intereses patriarcales que dominan a la sociedad costarricense en este periodo.

La socialización que reciben los niños y las niñas, va más allá de la enseñanza de quiénes son los que ejercen el control político en la sociedad costarricense y quiénes son los que se excluyen. De igual manera traslada ese aprendizaje a otras instancias de 
socialización que consolidan un engranaje, mediante el cual, el sistema patriarcal se afirma, consolida y reproduce.

¿De qué manera se instaura el sistema patriarcal en nuestra cultura? ¿Cómo y por qué la Educación Cívica es un transmisor y reproductor de ese sistema, en el período oligárquico liberal en Costa Rica? Esas interrogantes surgen a partir de estos planteamientos, y para ello se considera necesario recurrir a los elementos teóricos que nos ofrecen las perspectivas teóricas del género y de la educación cívica. A continuación se presentan.

\section{El sistema patriarcal}

Uno de los fundamentos sobre los cuales se erige la cultura occidental, es el patriarcalismo. Este es el sistema en el cual se produce el ejercicio del poder masculino sobre el femenino.

Su origen se remonta en el mismo inicio de los mitos fundamentados en el relato de la creación, cuando Dios Padre crea el mundo y a sus criaturas por el poder de su palabra pronunciada, y manifiesta así la superioridad divina que impregna el orden del universo. El Creador entrega al patriarca, jefe de la familia, el poder de organizar la vida política y social, para que legisle y diga cómo se debe vivir. Asimismo, instituye un aeda que comunica y transmite este orden, por medio de la creación artística.

De esta manera, a través de la acción divina, la acción terrena y la esfera de creación artística, se instala el patriarcado, el cual genera un círculo reiterativo que perpetúa el poder en torno a lo masculino, porque el elemento generador de todo lo válido presenta un rasgo común que es el dominio masculino.

Se instaura un centro masculino y un margen femenino, como una jerarquía profundamente asimétrica, donde el hombre, en primer lugar, se apropia del cuerpo de la mujer y luego establece su dominio sobre él. En las cosmovisiones y sociedades patriarcales, todo el género femenino es el segundo sexo. Como bien señala Simón de Beauvoir:

La historia ha mostrado que los hombres siempre tuvieron todos los poderes concretos, desde los primeros tiempos del patriarcado consideraron útil mantener a la mujer en un estado de dependencia, sus leyes se construyeron contra ella, así es como se convirtió concretamente en alteridad. (1949, p. 225) 
Desde esta perspectiva, el hombre construye un modelo de mujer a su medida; elabora un discurso a través del cual crea un conjunto de estereotipos que permanecen como modelos femeninos. Se le asigna los roles primordiales de madre abnegada y de esposa sumisa, dentro de un cuadro de atributos innumerables entre los cuales sobresalen, la pasividad, la irracionalidad y su carácter emocional entre otros. Señalan Gilbert y Gubar que:

Ello es así, precisamente porque a una mujer se le niega la autonomía..., no solo es excluida de la cultura, sino también se convierte en una encarnación de los extremos de la Otredad misteriosa e intransigente que la cultura enfrenta con adoración o temor, amor o aversión. Como fantasma, demonio y ángel, hada, bruja y espíritu... (1993, p.34)

Por otra parte, las mujeres ideales encarnan las virtudes del "eterno femenino": dóciles, puras, delicadas, castas, amables, de sentido justo, encerradas en su hogar se convierten en "el ángel de la casa". No son grandes ni extraordinarias en sí mismas, puesto que fueron creadas para el hombre y, por tanto, no tienen historia propia, religión, ni poesía que les pertenezcan auténticamente, "sueñan a través de los sueños de hombres" (Beauvoir, 1949, p. 228).

Puesto que las mujeres son definidas como plenamente pasivas, completamente vacías de poder generativo, como "ceros", (Gilbert y Gubar, 1993, p. 23) se llega incluso a una forma máxima de dominio y es lo que Kate Millet llama "colonización interior", una forma más resistente que cualquier tipo de segregación más uniforme, rigurosa y tenaz que la estratificación de las clases.

Aún cuando hoy en día resulte casi imperceptible, el dominio sexual es tal vez la ideología más profundamente arraigada, en nuestra cultura, por cristalizar en ella el concepto más elemental de poder (Millet, 1995, p. 70).

Según esta autora, es posible considerar la relación que existe entre los dos sexos, desde una perspectiva política, que se entiende como el conjunto de relaciones y compromisos estructurados, de acuerdo con el poder, en virtud de los cuales, un grupo de personas queda bajo el control de otro grupo y, en este sentido, el sexo es una categoría social impregnada de política, debido a que nuestras costumbres sexuales ponen de manifiesto, en el transcurso de la historia, una relación de dominio y subordinación. Ello se debe al carácter patriarcal de nuestra sociedad (Millet, 1995, pp. 68-70). Además señala: 
Recordemos que el ejército, la industria, la tecnología, las universidades, la ciencia, la política, y las finanzas -en una palabra, todas las vías de poder, incluida la fuerza coercitiva de la policía- se encuentran por completo en manos masculinas. Y como la esencia de la política radica en el poder, el impacto de ese privilegio es infalible (p.70).

La política sexual es objeto de aprobación, en relación con la socialización de ambos sexos según las normas fundamentales del patriarcado en lo que atañe al temperamento, al papel y a la posición social. Este esquema queda reforzado por el papel sexual que decreta para cada sexo, un código altamente elaborado de conductas, ademanes y actitudes. En el terreno de la actividad, a la mujer se le asigna el servicio doméstico y el cuidado de la prole, mientras que el varón puede ver realizados sus intereses y su ambición en todos los demás campos de la productividad humana.

Por lo tanto, la personalidad psicosexual es un conjunto de rasgos adquiridos con base en un aprendizaje que comienza desde el nacimiento, la identidad genérica, mujer-hombre, constituye la identidad primaria del ser humano. Señala Simon de Beauvoir: No se nace mujer: se llega a serlo.

Ningún destino biológico, psíquico, económico, define la imagen que reviste en el seno de la sociedad la hembra humana, el conjunto de la civilización elabora ese producto intermedio entre el macho y el castrado que se suele calificar de femenino. Solo la mediación ajena puede convertir un individuo en alteridad (1949, p.13).

¿Cómo se llega a ser mujer? Se aprende, a través de múltiples procesos que dan una educación diferenciada al hombre y a la mujer. La primera instancia de socialización, donde ocurre este aprendizaje, es en el seno de la familia.

El patriarcado gravita sobre la institución de la familia, la cual cumple un papel de mediadora entre el individuo y la estructura social. La familia y los papeles que implica son un calco de esta sociedad, al mismo tiempo que su principal instrumento y uno de los pilares fundamentales. No solo induce a sus miembros a adaptarse y amoldarse a la sociedad, sino que facilita el gobierno del estado patriarcal que dirige a sus ciudadanos por mediación de las cabezas de familia.

Debido a que la colaboración entre la familia y la sociedad resulta esencial para la supervivencia de ambas, los destinos de esas tres instituciones patriarcales que son la familia, la sociedad y el Estado se hallan íntimamente ligados entre sí. Cabe así explicar el apoyo prestado por la religión a la mayoría de los patriarcados, como 
demuestra el precepto católico de que el padre es la cabeza de la familia. Los gobiernos laicos contemporáneos también otorgan al varón el mando del hogar, como queda confirmado por los censos, la percepción de los impuestos, la reglamentación, y otros (Millet, 1995, p. 84).

El patriarcado decreta que tanto la posición del hijo, como la de la madre dependen, en definitiva, de la presencia de un varón. La figura masculina cobra en la familia -y fuera de ella- una fuerza ideológica y material, tanto más inquebrantable cuanto que las personas que están a su cargo dependen, a la vez, de su posición social y de su poder económico.

Así que, la principal aportación de la familia al patriarcado, es la socialización de los hijos de acuerdo con las actitudes dictadas por su ideología, en torno al papel, temperamento y posición de cada categoría sexual.

Aunque la familia constituye la primera instancia socializadora, en el plano educativo se establecen otros mecanismos que el patriarcado utiliza como recursos para ejercer su poder. En el plano institucional, las escuelas, colegios y centros de educación superior, también reproducen su ideología.

Como el patriarcado supone entre ambos sexos, una diferencia innata en lo que atañe a los rasgos de la personalidad, sus instituciones docentes aceptan una programación cultural que tiende a establecer una división general entre asignaturas "masculinas" y "femeninas"; asigna los estudios de letras y ciertas ciencias sociales (al menos las ramas inferiores o accesorias) a la mujer, y los estudios de ciencias, la tecnología, las profesiones liberales, los negocios y la ingeniería, al hombre. Por lo demás, estas últimas son especialidades favorecidas en el campo laboral, tanto por la remuneración, como por el prestigio de que son objeto.

El control de tales campos es en gran medida una cuestión política, ya que el dominio exclusivo que ejercen los varones sobre las profesiones más acreditadas protege los intereses del poder patriarcal en la industria, el comercio y el ejército (Millet, 1995, p.99).

Desde este punto de vista, la educación contribuye a fortalecer la posición inferior de lo femenino, en tanto jerarquiza los conocimientos por categorías sexuales que tienden a mantener a la mujer en estado de ignorancia. Hasta una época muy reciente, el patriarcado sólo permitía a la mujer, un mínimo de cultura en ciertos casos privilegiados (Mollet, 1995, p.98). 
Una de las materias que cumple ese papel idóneo para afirmar y reproducir el sistema patriarcal es la Educación Cívica. Las orientaciones teóricas que a continuación se presentan, detallan ciertas concepciones que tratan de dilucidar las funciones relativas a esta materia, la cual se presenta como un fenómeno educativo multidimensional, dirigido, en forma exclusiva, a la formación del ciudadano. En ese sentido, el lenguaje teórico que presentan los diferentes autores, no es inclusivo, debido a que hasta años muy recientes, se realiza todo un esfuerzo por emplear palabras con las cuales, las mujeres se puedan identificar y se sientan incluidas.

\section{Educación Cívica: Fenómeno educativo multidimensional}

La Educación Cívica se presenta como un fenómeno educativo multidimensional, ya que bien se puede hablar de una educación cívico-social, cívico-política, político-social, entre otras. La Educación Cívica es ciertamente educación moral y, aunque no coincida con la educación nacional, necesariamente la presupone dentro de sí.

\subsection{El carácter ético de la Educación Cívica}

Con respecto a la Educación Cívica, existen múltiples concepciones, pero una idea básica en donde coinciden diferentes autores, es que la cívica es la educación del hombre como ciudadano; lo cual implica que debe operarse una transformación.

Maillo García, por ejemplo, señala que ésta se propone la formación de ciudadanos, es decir, de miembros libres y responsables de la sociedad que ejerciten sus derechos y cumplan sus deberes con plena conciencia de ellos. Entiende por Educación Cívica

la que se propone la formación del ciudadano, o sea, aquella que prepara para comprender la sociedad a la que se pertenece, su situación en ella, los círculos que la integran y, en los cuales, el individuo se encuentra, directa o indirectamente, inmerso: es aquella educación que enseña las exigencias que se derivan de la plena inserción social, entre cuyas exigencias se destacan el ejercicio de los derechos cívico-políticos y el consiguiente cumplimiento de los deberes anejos a la condición de miembro de la sociedad políticamente organizada. (De la Rosa, 1977, p. 20).

Otros autores definen la cívica, dentro de la educación práctica y moral. Por consiguiente, debe abrir al educando a los valores, a la adquisición de sentimientos y virtudes. George Kerchensteiner, expresa que ser ciudadano significa servir a una idea moral, a un fin supremo que se halla fuera de nosotros. La Educación Cívica, por tanto, 
viene a ser sinónimo de educación para las virtudes de atención y de consagración a una suprema idea moral; esto es, sinónimo de educación del carácter desinteresado (1934, p.67).

A esta concepción Kerchensteiner agrega el cultivo de "verdaderas virtudes cívicas", tales como: reflexión, honorabilidad, constancia, circunspección, aplicación, amor al trabajo $y$, en consecuencia amor a la vida; respeto, sacrificio, de valor moral y de responsabilidad.

Por tanto, la Educación Cívica existe o no, según la educación de los sentimientos de justicia y equidad. Su fin primordial es lograr que el alumno desenvuelva el sentimiento de modestia, de responsabilidad para todo lo que habla, escribe y hace. En consecuencia, el fin más excelso de esta educación será formar a las personas en estos ideales, y esa misión debe comprender a todas las demás. El verdadero ciudadano es, pues, aquel que sacrificándose desinteresadamente, contribuye a la realización de la colectividad moral.

Objeto de la Educación Cívica, es pues, enseñar a los alumnos, en primer término una acertada estructuración de las escuelas, asociaciones, habituándose a sentir como un deber el progreso moral de la misma, ajustándose voluntariamente, con subordinación y respeto recíproco; y en particular sacrificándose personalmente y manteniendo siempre en alto la eficiencia moral (Kerchensteiner, 1934, p.61).

Esta concepción ética impregna la enseñanza de la Educación Cívica, sus contenidos, métodos y fines. De manera que al hablar de educación cívico-política, cívico-social, políticasocial, como fragmentos de una educación integral, el aspecto ético traspasa el umbral de todas ellas.

\subsection{Carácter cívico-político}

La educación cívico-política presupone el problema de la educación cívica de un pueblo y la educación del sentimiento nacional, por cuanto aglutina a los ciudadanos en torno a sus proyectos. Su fin es la realización de la idea de una comunidad moral en un ideal nacional; es decir, el ideal de un Estado culto y jurídico. Además conforma el ideal de un Estado de derecho, en cuanto la comunidad perseguida debe regular las relaciones según las normas de la justicia y de la equidad.

..., el objeto de la Educación Cívica consiste en educar a los ciudadanos de forma que sus actividades, consciente $\mathrm{o}$ inconscientemente, directa o indirectamente, se pongan al servicio del Estado que aquellos constituyen, para lograr ese ideal infinitamente 
lejano de una colectividad moral, esto es, de una comunidad de ciudadanos en la que el orden jurídico nacional no precisa de ningún poder coercitivo (Kerchensteiner, 1934, p.62).

Por estos motivos, la Educación Cívica presupone un concepto ético del Estado, bajo una concepción ideal que se quiere alcanzar. Es la imagen de un Estado jurídico y cultural, donde la lucha de intereses e ideas busca y halla equiparación en un sentido cada vez más digno y humano, en que finalmente coinciden los intereses del Estado con los armónicos intereses de todos. Se sabe que es una concepción ideal, pero esa imagen sirve de apoyo a la constitución y a las instituciones existentes para lograr mantener la esperanza de alcanzar sus fines.

De allí que es necesario inculcar la idea de autoridad y sus poderes, las formas de gobierno y la participación del individuo en las tareas del Estado y a la alta política que sabe disponer los medios para los fines (De la Rosa, 1977, p.23).

Así que, la Educación Cívica no es solamente un problema relacionado con la formación del dirigido, sino también, y ante todo, del director en la medida que

... el fin supremo de la Educación Cívica es formar el sentimiento ético estatal; pero éste no consiste en otra cosa sino en hallarse poseído de la idea moral del Estado y en hallarse dispuesto, por propia acción y omisión, a colaborar en el desenvolvimiento del Estado existente en el sentido de la idea ética estatal (Kerchensteiner, 1934, p.63).

Uno de los elementos que permite forjar ese sentimiento ético estatal, es infundir el amor a la patria. De esta forma la educación política se apareja con la educación patriótica debido a que

... el amor a la patria sin formación política viene a ser como un globo sin dirección, y la formación política sin educación cívica es un dirigible sin brújula ni carta de navegación (Kerchensteiner, 1934, p. 45).

Igualmente, el amor patrio se interpreta como fidelidad a la cultura nacional, la cual debe disponer de los medios para lograr una lealtad amplia. Es por eso que la cívica cumple también este papel. 


\subsection{Carácter cívico-social}

La Educación Cívica es una parcela concreta y determinada, dentro de la educación social y, como tal, debe capacitar para la convivencia. Debe abrir al estudiante a los valores y a las realidades culturales, económicas, sociales y espirituales; debe proveerle y equipararle para todas las relaciones que mantenga, ya sean de parentesco, camaradería, de negocios, de civilidad, entre otros.

La Educación Cívica tiene por objeto hacer al niño apto para convivir con los demás, para trabajar con ellos por el bien común, y a mantener relaciones de estimación hasta con los miembros alejados, de los que solamente conoce su existencia. (De la Rosa, 1977, p. 21)

Así concebido, el carácter cívico-social adquiere una concepción pluridimensional que afirma el sentimiento de comunidad en la formación del futuro ciudadano. Desde esta perspectiva, adquiere importancia el trabajo colectivo, en la medida que crea las condiciones fundamentales para que la vida social influya en el Estado.

Este trabajo colectivo debe proporcionar valiosas virtudes sociales, tales como: subordinación voluntaria del estudiante y obediencia debida a jefes elegidos por ellos mismos, la buena disposición a sacrificarse en favor de las necesidades espirituales y morales de sus condiscípulos y la virtud del justo respeto, todo eso asociado al valor moral y al indispensable sentimiento de responsabilidad: "solamente entonces podrá encontrar también la instrucción cívica en sentido estricto el terreno propicio que necesita para obtener buenos frutos" (Kerchensteiner, 1934, pp. 70-72). En consecuencia, la escuela es la que debe iniciar al niño en la enseñanza de los deberes más que de los derechos

Es una enseñanza de deberes en el sector de las actividades profesionales en que la escuela procura iniciar a los alumnos, dentro de las instituciones y normas del organismo escolar establecido sobre un trabajo colectivo espiritual y material, organismo que se amplía mediante la consideración de la esfera de acción de la colectividad, inmediata al estudiante, y que finalmente se cierra con el estudio del círculo de deberes para con el Estado, colectividad que aparece algo más alejada del alumno. (De la Rosa, 1977, p. 33)

La escuela primaria es, pues, la colectividad escolar que puede enseñar a los niños:

1. Lo que ofrece la colectividad mediante las instituciones tutelares públicas.

2. Los deberes que incumben a cada miembro de la colectividad. 
3. La acción recíproca que se establece entre las características de una comunidad, basada en la justicia y la fraternidad y la moralidad de cada uno de sus miembros.

4. La significación de ser miembro o ciudadano de una comunidad familiar, escolar, local, provincial o nacional y las aspiraciones que ha de mantener y satisfacer, y qué instituciones deberán defender con máximo ardor.

Así, la enseñanza de la cívica propicia la iniciación a la vida social a través del contacto en la escuela y, particularmente, en sus actividades para escolares.

\subsection{Dualismo instrucción-educación}

La Educación Cívica tiene a su alcance, diversas fuentes de conocimiento, las cuales van desde las enseñanzas específicas de su propio programa académico, hasta la participación en las distintas actividades de la vida familiar, escolar, profesional, local, nacional e internacional.

La enseñanza de la cívica se presenta bajo la perspectiva de dos dimensiones: a) como iniciación a la vida social y b) una enseñanza teórica, dentro de un horario general docente, utiliza técnicas pedagógicas que propician una mayor participación. Según este punto de vista, se admite la importancia de los conocimientos cívico-sociales que no pueden reducirse, ni a la pura "práctica" ni a rígidos programas desprovistos de vida y de real aplicación con el entorno convivencial.

Difícilmente podremos obtener, en la complejidad de las estructuras sociales, una sólida formación cívica sin unos conocimientos, sin unos contenidos instructivos, reglados incluso programáticamente, que sirvan de base cognoscitiva imprescindible para conocer la comunidad en la que estamos obligados a insertarnos (De la Rosa, 1977, p. 30).

Desde la perspectiva moral, la Educación Cívica se resiste a ser enseñada, en el sentido puramente instructivo del término, debido a que la moral es acción y, por lo tanto, no puede ser objeto de lecciones, bajo el mismo punto de vista de las materias de orden intelectual. La necesidad del dualismo educación-instrucción se pone de manifiesto, en cuanto a la cívica se refiere.

Consecuentemente un ambiente de moralidad, de sociabilidad o de civismo, ha de rodear y estimular al educando, mucho antes de hacerles aprender contenidos teóricos 
sobre los temas que provean al niño, una instrucción cívica que proporcione los conocimientos indispensables para entender el funcionamiento de la vida social.

Por su parte, la Instrucción Cívica proporciona los asideros intelectuales, donde encontrarán fundamento y motivo las tendencias sociales antes adquiridas, de tal modo que les sirven de cuadro mental capaz de orientarlas y de darles consistencia y sentido. El contenido de esta instrucción es bastante amplio; comprende patrimonio cultural (fuentes de prosperidad, folklore, usos, costumbres, arte, historia patria), así como el conocimiento de las diferentes regiones, y el funcionamiento de las instituciones del Estado, de la provincia, del municipio y de todo lo concerniente a la vida en comunidad (De la Rosa, 1977, p.32).

Sin embargo, se trata de conocimientos que deben llevarse a la práctica en la actuación moral. Este tipo compone una gran parte de los conocimientos cívicos.

Las enseñanzas de civismo, legislación, constitución, economía, los estudios de los fines e instituciones del Estado y, sobre todo, de los derechos y deberes del ciudadano serán provechosas cuando evitando la adquisición de conocimientos por procedimientos memoristas esas ideas caigan sobre un terreno: a) bien dispuesto a la actuación cívica por un férreo cultivo de las buenas costumbres, y b) ya abonado y preparado por un sentimiento ético (Kerchensteiner, 1934, p. 35).

Limitarse a exponer a los educandos cuántos ministerios tiene un Estado: ¿cómo está organizado el Parlamento, la justicia y la administración?, ¿cómo debemos comportarnos con las autoridades nacionales?, ¿cuáles son los puntos esenciales de un contrato de aprendizaje o de un seguro de trabajo? y otros, no es ni mucho menos el fin más elevado de la Instrucción Cívica. Pero el fin de esta Educación, es conducir al estudiante al logro de las virtudes primordiales que encierran un valor ético.

El éxito de esta educación depende de la medida en que el educador logre asociar y fundir, por el hábito y la persuasión, los fines que se propone. "Incluso el adiestramiento se alcanza mejor mientras no se pierda de vista este principio" (Kerchensteiner, 1934, p.57).

En consecuencia la enseñanza de la Educación Cívica no puede comprenderse, sin esta posibilidad de instruir sin educar. Instruir equivale a proporcionar, proveer, equipar, es decir informar. Educar en cambio, tiende a conducir, guiar, es decir, formar. Para que esta Educación Cívica sea eficaz, se necesita un programa, un método, una documentación y un docente (De la Rosa, 1977, p.33). El docente, además, debe desempeñar su papel como reproductor de las labores socializadoras e ideológicas que presenta la educación en un sentido más general. 
En Costa Rica, desde épocas muy tempranas en el desarrollo del Estado Nacional, el discurso político costarricense es reiterativo en cuanto a las representaciones que consolidan un sistema de organización democrático. Alrededor de ese discurso, concurren una serie de concepciones e ideas que corresponden al campo de lo cívico. Desde ese entonces, existe un marcado interés por inculcar y difundir los conocimientos, valores, actitudes y comportamientos que lo cívico involucra.

La escuela se constituye en el medio idóneo para transmitir e institucionalizar un discurso cívico, a través de la enseñanza de una materia que, en forma concreta, enseñe a los niños, no así a las niñas, los conocimientos y representaciones propios de la Educación Cívica.

Tal como se mencionó anteriormente, en el año de 1886, se lleva a cabo en el país la Reforma Educativa. Es entonces cuando se introduce, de manera permanente en los planes de estudio, la Instrucción Cívica como materia obligatoria, su objetivo primordial es formar ciudadanos, (en el sentido literal del término), idóneos para la patria. Con su establecimiento, se trata de difundir por medio del sistema educativo una serie de concepciones, símbolos y valores que hoy por hoy se consideran categorías o atributos propios de la identidad, nacionalidad e idiosincrasia de los costarricenses, tales como: democracia, paz, libertad, igualdad y legalidad entre otros.

La Educación-Instrucción Cívica se constituye en una materia que mediante la difusión de una serie de contenidos y valores diferenciados para los niños y las niñas, permite la construcción o formación de una ciudadanía preponderantemente masculina, y lo hace desde múltiples perspectivas que incluyen factores políticos, económicos, sociales, culturales y sexuales. Por lo demás, cumple su cometido en el ámbito de lo ideológico y del imaginario colectivo. Su discurso moral e intelectual constituye uno de los fundamentos, por medio del cual, se nutre y fortalece el sistema patriarcal a través de la ideología dominante en el período oligárquico liberal en Costa Rica. 


\section{Los contenidos diferenciados que la Instrucción Cívica enseña a los niños y a las niñas en el período 1886-1920}

Los contenidos que presentan los programas ${ }^{2}$ oficiales que se establecen para este período, están dirigidos fundamentalmente, a la formación del niño, en el sentido literal de la palabra. Al niño se le llama la atención, para que "atienda el magnífico espectáculo de la salida y la puesta del sol", se le explica el "importantísimo oficio que desempeñan los sentidos", se le inculcan las buenas costumbres y fomentan sus buenas cualidades, igualmente, se le enseñan los deberes para consigo mismo, la familia y la sociedad, así como sus deberes y derechos de ciudadano, entre otros (Programas Oficiales, 1890).

Debido a que el patriarcado gravita sobre la institución de la familia, este tema se constituye en uno de los ejes imprescindibles comunes de todos los programas de Moral e Instrucción Cívica. Efectivamente, en estos programas, se considera a la familia como "la piedra angular de la sociedad". Y a partir de ella se establece una jerarquía de valores, virtudes y deberes que inducen a sus miembros a amoldarse a la sociedad para facilitar el gobierno patriarcal.

Al respecto, en forma textual, el programa escolar que se imparte para las escuelas a fines del siglo XIX, expone que sobre la familia se deben estudiar los siguientes aspectos:

A. ..., quienes la componen. Virtudes domésticas: solidaridad. La autoridad paterna. El abuelo y el nieto. Encantos del hogar. Conservar inmaculado el nombre de nuestros padres. B. Obligaciones Imperiosas del hijo: cariño, sumisión, gratitud, respeto. Caracteres de un buen hijo. El hijo desnaturalizado (contrastes). La abnegación. La docilidad, deber fundamental del niño. Nuestros padres en la vejez, en la miseria en la adversidad. C. Deberes recíprocos de los hermanos. Solidaridad, unión. Papel del hijo mayor cuando faltan los padres. D. Amos y criados, patrones y obreros: deberes recíprocos, probidad y honradez en el que sirve. El salario equitativo (ANCR, No. 4613).

El señalamiento de estos contenidos constata la forma en que la sociedad patriarcal costarricense de este período presenta como elemento primario de autoridad, al "pater familias", dentro de una organización jerárquica de poder, que adquiere eminentemente, una

${ }^{2}$ En el transcurso de este período se establecen oficialmente, para la enseñanza de la Moral e Instrucción Cívica, tres programas: el primero de ellos, no tiene una fecha específica sino que se presume es de fines del siglo XIX, los otros dos corresponden a los años de 1890 y 1909. 
condición hereditaria, dirigida hacia el hijo mayor en primera instancia y, a los otros hijos de manera secundaria. La mujer está ausente dentro de esta distribución de poder que adicionalmente, establece parámetros de obediencia y sumisión, porque le asigna al "hijo" una serie de obligaciones imperiosas (sumisión, respeto, abnegación, docilidad) que debe conservar y transmitir, por lo cual, se reproduce un "natural" ordenamiento, que vacía a la mujer de poder generativo, se constituye así, en la ausencia de la presencia.

Así como la familia instaura y el orden patriarcal, el sistema educativo también lo reproduce, ya que le asigna a la escuela una "misión social" y, al maestro, la función de "representante de la familia y del Estado". Igualmente, se determinan una serie de obligaciones y deberes al "alumno": docilidad, aplicación, disciplina y veneración para el maestro.

¿Qué les enseña la Moral e Instrucción Cívica en la escuela a las niñas y a los niños en este período?

Como anteriormente se mencionó, los contenidos están dirigidos fundamentalmente hacia los niños, sin embargo en el programa oficial para el año de 1909, como una nota de pie de página se establece que en las escuelas de niñas

se darán nociones de Economía doméstica: cocina; además, cochura del maíz, frijoles, carnes y verduras; preparación de algunos platos; fabricación del queso; conservación de la leche y mantequilla; cría de aves de corral. Estas lecciones serán en lo posible experimentales (Programas Oficiales, 1909).

Pero a los niños se les enseña entre otros elementos:

Virtudes cívicas. La sumisión a las leyes. El impuesto (el contrabando es un robo) El servicio militar (obligatorio para todos). La traición es el más cobarde de los crímenes. El voto, moralmente obligatorio (indeferentismo político). Educación Obligatoria. El Patriotismo: caracteres del verdadero patriota. Monstruosidad del asesinato político. Altos ejemplos de patriotismo (en Plutarco, Varones ilustres). Biografías de patriotas costarricenses. Anécdotas y episodios de la campaña nacional. (Programas Oficiales, Fines del siglo XIX).

La diferencia de contenidos es incuestionable; mientras que a las niñas se les enseña elementos de economía doméstica para que desempeñe con su función de "ángel de la casa" y educadora de los hijos, también la circunscriben al ámbito doméstico y, 
adicionalmente le niegan la participación en los espacios políticos del país. Todavía en 1926 se expresa:

¡Mujer y hogar! No se comprende el uno sin el otro. La primera obligación de la mujer, es ser mujer de su casa, la primera obligación del hogar y de la escuela es capacitarla para ello. (La Gaceta, 1926, p. 702)

A los niños por el contrario se les inculca las virtudes cívicas que los capacitan para ser los futuros ciudadanos (en la medida que los mecanismos de exclusión que presentan las leyes, les permitan ejercer efectivamente esa función), defensores de la patria, ciudadanossoldados, posibles héroes nacionales. Por eso, entre los contenidos que se imparten, también se les enseña los rasgos notables de personajes históricos y se prefieren aquellos que son modelos de firmeza de carácter, hidalguía, generosidad, solidaridad y patriotismo.

Asimismo, los programas son muy enfáticos al establecer la forma de enseñar estos contenidos. Puesto que para el aprendizaje de la Cívica, se da la fusión InstrucciónEducación; se recomienda al maestro "dirigir e ilustrar la conciencia del niño, y disponerle al bien, formarle el carácter y reaccionar contra sus bajas inclinaciones.

No olvide el maestro que la moral debe inculcarse antes de enseñarse. Las definiciones son cosa accesoria y en todo caso fuerza es deducirlo del hecho real y concreto. Sírvanle las máximas, sentencias, cuentos biografías, y otros. Para fijar la lección y comunicar vida y calor a la palabra. (Programas Nacionales, Fines del siglo $\mathrm{XIX)}$

La presencia de estos contenidos y valores, y la forma de enseñarlos, podrían plantearse, como una de las tantas representaciones que manifiestan el conjunto del sistema de valores de la ideología dominante durante estos años en la sociedad costarricense. A través, de la educación se trata de moldear el carácter de los niños y niñas a los cuales se les asignan códigos de conductas para que desempeñen su rol genérico. Los valores así transmitidos, propician que desde la edad escolar aprendan y perpetúen un orden jerárquico de sumisión, autocensura y autocontrol.

Además, se orienta a los estudiantes hacia la legitimación de un determinado orden político, económico, social y cultural; a justificar, mantener y transmitir los intereses de las clases rectoras. Por estos mismos medios, se trata de establecer una moral pública que facilite el control ideológico de dominación. A través de una doble moral: la moral de las clases dominantes y la moral de las clases subalternas, se pretende legitimar un régimen de 
desigualdad, injusticia, opresión y altamente excluyente, particularmente en cuanto a lo femenino se refiere.

Desde este punto de vista, es indiscutible la forma en que los contenidos de la Instrucción-Educación Cívica muestran cómo el dominio sexual es la ideología más profundamente arraigada en nuestra cultura y cómo cristaliza en ella el concepto más elemental de poder. Se pone de manifiesto un conjunto de relaciones y compromisos fuertemente estructurados de acuerdo con el poder, en virtud de los cuales un grupo de personas queda bajo el control de otro grupo. El sexo se presenta como categoría social impregnada de política, debido a la forma en que la clase dominante del período oligárquico liberal en Costa Rica, estructura el ejercicio del poder masculino sobre el femenino en el transcurso de la historia. 


\section{REFERENCIAS}

Archivos Nacionales de Costa Rica. (s.f.). Serie Educación. No. 4613. Programa de Moral. Documento sin fecha que se presume es de fines del siglo XIX.

Archivos Nacionales de Costa Rica. (1986) Serie Congreso. N. 9113. Folio 26. San José: C.R.: Asamblea Legislativa

Archivos Nacionales de Costa Rica. (1986) Serie Congreso. No. 9113. Folio 2. San José: C.R.: Asamblea Legislativa

Beauvoir, S. (1949). EI Segundo Sexo. Madrid, España: Ediciones Cátedra.

De la Rosa Acosta, B. (1977). Educación Cívica y Comprensión Internacional. España: Ediciones CEAS. S.A.

Gilbert M., S. Gubar, S. (1993). La Loca del Desván. Madrid: Ediciones Cátedra.

Jiménez, R. (1898). Instrucción Cívica. San José, C.R.: Imprenta y Librería Española de María v. De Lines.

Kerchensteiner, G. (1934). La Educación Cívica. Barcelona: Editorial LABOR. S.A .

La Gaceta. (23 de mayo de 1926). San José, C.R.: Imprenta Nacional.

Memorias de Instrucción Pública. (1885). San José, C.R.: Imprenta Nacional.

Millet, K. (1995). Política Sexual. Valencia: Ediciones Cátedra.

Monge Alfaro, C. y Rivas Ríos, F. (1984). Educación Fragua de Nuestra Democracia. San José, C.R.: Editorial de la Universidad de Costa Rica.

Programas Oficiales de Instrucción Primaria de la República de Costa Rica. (1909). San José, C.R.: Tipografía Nacional.

Programas Oficiales de Instrucción Primaria. (1890). San José, C.R.: Tipografía de la Prensa Libre. 